\title{
A comprehensive review and update on severe acute respiratory syndrome coronavirus 2 (SARS-CoV-2) and Coronavirus disease 2019 (COVID-19): what do we know now in 2021?
}

\author{
Kamleshun Ramphul ${ }^{1}$, Yogeshwaree Ramphul ${ }^{2}$, Yun Park ${ }^{3}$, Petras Lohana ${ }^{4}$, \\ Balkiranjit Kaur Dhillon ${ }^{5}$, Shaheen Sombans ${ }^{6}$
}

\author{
${ }^{1}$ Department of Pediatrics, Shanghai Xin Hua Hospital, Shanghai Jiao Tong University, \\ School of Medicine, Shanghai, China \\ 2Department of Medicine, Sir Seewoosagur Ramgoolam National Hospital, \\ Pamplemousses, Mauritius \\ ${ }^{3}$ Department of Orthodontics, Shanghai Jiao Tong University, School of Medicine, \\ Shanghai, China \\ ${ }^{4}$ Department of Medicine, Liaquat University of Medical and Health Sciences Hospital \\ Jamshoro, Pakistan \\ ${ }^{5}$ Department of Medicine, Baba Farid University of Health Sciences, Punjab Medical, \\ India \\ ${ }^{6}$ Department of Medicine, Bharati Vidyapeeth University Medical College and Hospital, \\ Pune, India
}

Submitted: 5 February 2021

Accepted: 1 March 2021

Arch Med Sci Atheroscler Dis 2021; 6: e5-e13

DOI: https://doi.org/10.5114/amsad.2021.105065

Copyright (c) 2021 Termedia \& Banach

\section{Abstract}

It has been more than a year since the new virus called severe acute respiratory syndrome Coronavirus 2 (SARS-CoV-2) was identified in Wuhan, China. The disease it causes was named Coronavirus disease 2019 (COVID-19), and on 11 March 2020 it was declared a pandemic. As the virus continues to spread, the number of patients worldwide has already crossed the 100 million mark with more than 2 million deaths. We sought to provide an update on the progress made in identifying the virus, its pathophysiology, risk factors such as hypertension, diabetes, and smoking, as well as various methods of treatment. Our review also provided an overview of the different vaccines.

Key words: severe acute respiratory syndrome coronavirus 2, SARS-CoV-2, Coronavirus disease 2019, COVID-19, pandemic.

\section{Introduction}

In early December 2019, a group of patients from Wuhan City, China reported symptoms of pneumonia of unknown origin [1]. The patients had all recently been exposed to the Huanan Seafood Wholesale Market [2]. The respective Chinese Health departments and the World Health Organization (WHO) were informed of the situation. The first report consisted of 44 patients, amongst whom 11 were severely ill. Their main symptom was fever, and some patients had difficulty breathing, with invasive lung lesions seen bilaterally [3]. Genomic sequencing was performed to identify the new agent, which was first named 2019-nCoV

\author{
Corresponding author: \\ Dr. Shaheen Sombans \\ Bharati Vidyapeeth \\ University Medical \\ College and Hospital \\ Pune, India \\ Medical College Road \\ Pune - Satara Rd \\ Dhankawadi, Pune \\ Maharashtra 411043 \\ India \\ Phone: +9193737 28706 \\ Email: drshaheensombans@ \\ gmail.com
}


$[4,5]$. Because the virus was closely related to severe acute respiratory syndrome (SARS) coronavirus (SARS-CoV), the name was changed to severe acute respiratory syndrome coronavirus 2 (SARSCoV-2), and the disease it causes was called Coronavirus disease 2019 (COVID-19) [1, 6]. The WHO raised warning concerns and labelled it as a public health emergency of international concern on 30 January 2020. The virus started to spread, first throughout China, and then internationally. It was officially declared a pandemic on 11 March 2020 $[1,2]$.

Fast-forward a year, and the world is still struggling to control the spread of the virus, with many countries in lockdown or with their international borders closed. Many hospitals are overloaded with sick patients and the death toll keeps rising daily. This review aims to provide an in-depth understanding of the virus, its pathophysiology, epidemiology, as well as the clinical management while reflecting on what the future holds with the current situation.

\section{Virology: what is SARS-CoV-2?}

SARS-CoV-2 originates from the coronavirus family and is an enveloped, single-stranded RNA virus. Two other members of that family of virus include severe acute respiratory syndrome (SARS) and Middle East respiratory syndrome (MERS) [1, 7]. SARS appeared between 2001 and 2003, causing the deaths of 774 people. Between 2012 and 2015, MERS was reported to kill 858 people [8]. Another manifestation of the coronavirus family includes the common cold. While SARS-CoV-2 has several similarities with other members of the coronavirus family, several major differences in pathology and prognosis have been reported $[1,9,10]$.

An early analysis of 10 genomic sequences was obtained by Lu et al. from 9 patients who were exposed to the Huanan Seafood Market in Wuhan, China. They reported that the new virus had a similarity of $88 \%$ with two previously reported sequences of SARS-CoV, i.e. bat-SL-CoVZC45 and bat-SL-CoVZXC21, which were both bat derived. Less similar correlations were found with SARSCoV (79\%) and MERS-CoV(50\%) [11]. The virus has 6 main functional open reading frames (ORFs) called Replicase (ORF1a/ORF1b), Spike (S), Envelope (E), Membrane (M), and Nucleocapsid (N) [12]. Hu et al. compared the proteins, listing more than $90 \%$ similarity in the amino acid identity between SARS-CoV2 and SARS-CoV [13]. The S gene, however, showed major differences [13-15].

Chen et al. identified the entire genome to be 29,881 bp long, which encodes for 9860 amino acids. The surface of the virus contains multiple TM protease serine 2 (TMPRSS2) glycosylated proteins called $\mathrm{S}$ proteins. They help the virus bind to the host receptor angiotensin-converting enzyme 2 (ACE2), which then promotes the entry of the virus into host cell via a type 2 TM serine protease called TM protease serine 2 (TMPRSS2) [16]. The viral RNA is transcribed, translated, and replicated inside the host cell [17].

Multiple variants have been reported for the virus [12]. The B.1.1.7 lineage was initially isolated in the United Kingdom in late 2020. This mutated virus has been linked with a higher risk of infectivity (50-75\% higher). The presence of the strain was also eventually confirmed in other countries $[18,19]$. The B.1.351 lineage was found in South Africa. It has an N501Y mutation in the spike protein $[12,20]$.

The main route of transmission is person-toperson via respiratory droplets. Close-range contact within 2 metres can infect another person if the droplets are inhaled or make contact with the mucous membranes [12, 21, 22]. Contaminated surfaces may also be a source of infection. The virus has also been detected in stool, blood, semen, and even ocular secretions [12]. While the virus can have an incubation period of around 14 days, many cases have been reported within 4-5 days of exposure [12, 23-25].

\section{Epidemiology of COVID-19}

By 10 March 2020, there had been 113,702 reported cases of COVID-19 in the world, and 4012 patients had died. At that time, the United States had only had 472 cases with 19 deaths, and South Korea, Japan, and Italy were the countries outside of China with the highest incidence of the disease [1]. However, as of 1 February 2021, there are now $103,741,860$ confirmed cases of COVID-19 across the world and 2,243,354 people have died of the virus [26]. Cases of COVID-19 have been reported across all continents except for Antarctica, and it is believed that the actual number of infected individuals might be as much as 10 times higher than the reported number $[12,27,28]$. The United States currently has the highest number of total reported cases of COVID in the world with 26,796,980 infected Americans. It also has the highest total deaths due to COVID-19, as 452,921 have died since the virus was first confirmed in the country on 20 January 2020 [29]. India has the second-highest number of total cases with $10,767,159$ confirmed cases, while Brazil is third with 9,204,731 patients [26].

\section{Clinical findings}

The range of clinical symptoms can vary from asymptomatic to severe or even death. Diagnosis can be made via nucleic acid-based tests, and the use of reverse-transcriptase polymerase chain reaction (RT-PCR) from various samples is a gold 
standard method of confirming an infection [30]. As per the Centers for Disease Control and Prevention $(C D C)$ in the United States, the common symptoms can include fever (43\%), chills, cough (50\%), shortness of breath (29\%), headache (34\%), new loss of taste or smell $(<10 \%)$, sore throat (20\%), diarrhoea, nausea/vomiting (12\%), congestion, muscle ache (36\%), and fatigue [31, 32]. Eighty-nine percent of patients who lost their sense of smell or taste reported that it improved over the next 4 weeks [33]. An early report by the Chinese Centre for Disease Control and Prevention showed that $81 \%$ of patients had mild disease, which may or may not include mild pneumonia. Fourteen per cent showed several severe symptoms such as dyspnoea, hypoxia, or at least $50 \%$ of lung involvement on imaging after 1-2 days. Five percent of those affected in their report had critical disease, which included respiratory failure, shock, or multiple organ dysfunction. They also reported a fatality rate of $2.3 \%[12,34]$. In a meta-analysis conducted by Meyerowitz-Katz et al., the infection fatality rate (IFR) was estimated at $0.68 \%$ [35]. An overall infection fatality risk of $0.8 \%$ was reported in Spain [36].

Several possible risk factors such as a history of hypertension, diabetes, smoking, previous cerebrovascular disease, acute or chronic kidney injury, and chronic obstructive pulmonary disease have all been linked with severe COVID-19 [3742]. Several laboratory findings such as thrombocytopaenia, low haemoglobin value, and elevated red blood cell distribution width (RDW) have also been associated with a more critical prognosis of the disease [43-47]. Some clinical symptoms such as myalgia and headache do not predict severity $[48,49]$. While COVID-19 can present in people of all ages, middle-aged and older adults were more commonly affected than children. Older age was associated with a higher hospitalization rate and also a higher risk of mortality [34, 50-52]. Men have a higher risk of developing a critical outcome or death than females [50-61]. Several ethnic differences linked with socio-economic and social determinants of health have also put African Americans, Hispanics, and South Asians in the high-risk group [12, 50, 57-61].

Some rare cases of multisystem inflammatory syndrome in children (MIS-C) have been reported by the CDC in children who have been exposed to COVID-19 or have been around someone with the disease. MIS-C has several similarities and differences with Kawasaki disease $[62,63]$. It can affect the heart, lungs, kidneys, as well as the gastrointestinal system and present with a myriad of symptoms [64]. The CDC has established the definition for MIS-C as a patient of age less than 21 years, having a fever of at least $38.0^{\circ} \mathrm{C}$ for at least $24 \mathrm{~h}$ or subjective fever lasting more than $24 \mathrm{~h}$, as well as evidence of inflammation such as "an elevated C-reactive protein (CRP), erythrocyte sedimentation rate (ESR), fibrinogen, procalcitonin, d-dimer, ferritin, lactic acid dehydrogenase (LDH), or interleukin 6 (IL-6), elevated neutrophils, reduced lymphocytes, and low albumin". These individuals should also be ruled out for any other possible cause, and they should have a positive current or recent SARS-CoV-2 infection confirmed via RT-PCR, serology, or antigen test. Alternatively, they should have been exposed to someone who is a confirmed or suspected case of COVID-19 within the last 4 weeks before the onset of their clinical findings [65].

The most common symptoms in pregnant women are cough and fever, and they have a mild course of illness that will not affect their delivery. However, pregnancy increases the risk of a more severe outcome of COVID-19 that may require intubation or mechanical ventilation. Boushra et al. found that pregnant women are at the highest risk of critical outcome needing intensive care admission or mechanical ventilation during their third trimester. This puts the foetus at a risk of miscarriage, foetal growth restriction, or even prematurity [66]. In the study conducted by Kotlyar et al., the risk of vertical transmission during the third trimester was found to be $3.2 \%$ [67].

\section{Management of COVID-19-positive patients}

There are multiple guidelines for the management of COVID-19 based on symptoms and severity $[68,69]$. The guidelines by the National Institutes of Health (NIH) are based on scientific data and well-established discussions highlighting the risks and benefits of each treatment in patients. Changes in protocols reflect the evolving knowledge about the virus, its pathophysiology, and response among several different strains [69]. The decision to hospitalize a COVID-19 patient depends on the physician's judgment based on the severity of the patient's condition as well as the prioritization of the resources according to the number of cases and hospital beds available. Several triage protocols have been established to provide fairness and also to improve the quality of care while improving the response of hospital systems $[68,69]$. Many mild cases of COVID-19, i.e. without pneumonia or hypoxia, may not need hospitalization. However, their situation should be properly monitored, and the final choice to pursue outpatient or inpatient care should be on a caseby-case basis [70, 71].

Severe cases of COVID-19 usually require hospitalization. They need supportive care for their symptoms and proper management to prevent complications. Their pneumonia, hypoxaemic 
condition, any sepsis or shock, as well as any organ damage should be addressed promptly. More than $75 \%$ of hospitalized COVID-19 patients required supplemental oxygen, and those who do not improve with conventional oxygen therapy are usually given heated high-flow nasal cannula oxygen. Additional techniques to improve their oxygenation such as prone positioning or the use of cisatracurium can also be adopted as needed $[72,73]$. Their bleeding profile and other laboratory findings should be carefully monitored because COVID-19 positive patients are also at risk of multiple complications such as thromboembolism [71]. Imaging of the chest should be evaluated for findings such as ground glass appearance, and their progress should be tracked as per protocol [74]. Dexamethasone can be used with severe cases of COVID-19 who are also on ventilator support or require additional oxygen. Ahmed et al. reported that low doses can be useful in severe cases but do not show any positive impact on mortality for mild cases [75]. Tomazini et al. concluded that the use of intravenous dexamethasone along with standard care helped increase the number of ventilator-free days [76]. Data showed that the use of dexamethasone is more beneficial than other glucocorticoids at equivalent doses. The side effects of the drug should be carefully monitored. In a meta-analysis conducted by the WHO Rapid Evidence Appraisal for COVID-19 Therapies (REACT) Working Group, it was found that there is a lower 28-day all-cause mortality in patients using systemic corticosteroids compared to usual care or placebo [12, 77].

In the early months of the pandemic, the drugs chloroquine (CQ) and hydroxychloroquine (HCQ) were among the treatment options for COVID-19. However, in June 2020, the US FDA re-evaluated the use of these drugs and revoked their emergency use authorization. Both drugs are weak bases that interfere with the multiplication of a virus by affecting its entry through endosomes. Yao et al. also reported that hydroxychloroquine showed higher potency against the virus than chloroquine [78]. However, several articles and analyses eventually found that the use of the drug did not confer any improvement among several patient groups in terms of clinical status or mortality $[71,79,80]$.

Remdesivir has previously shown a wide spectrum of antiviral properties. When used with MERS-CoV, the drug helped improve disease outcomes and pulmonary function [81]. Monotherapy of remdesivir for severe COVID-19 helps shorten recovery. It has also been useful in reducing mortality in severe COVID-19 cases that are using lowflow supplementary oxygen. The drug has also been approved by the FDA in the US to be used for children of at least 12 years of age and adults [12, 81-83].
Convalescent plasma from patients who have been COVID-19 positive and recovered at least 2 weeks prior is another therapy being used during the pandemic [71]. These patients have high levels of neutralizing antibodies, and their plasma can be used through the emergency use authorization issued in the United States. Its benefits for severe cases of COVID-19 are, however, still not fully understood $[84,85]$. The plasma provides neutralizing antibodies that target the virus and prevent its entry into cells and enhance its clearance. Once administered, there is an initial wait of 2 to 3 weeks before a proper response is provided by the recipient $[12,71]$.

Because the pathophysiology of COVID-19 involves several cytokines including IL-6, various drugs that work against IL- 6 have been tested as a possible therapy. Tocilizumab and sarilumab are receptor blockers, and siltuximab is a direct inhibitor. However, their use is not standard and should be evaluated on a case-by-case basis [1, 12]. Baricitinib is another drug that provides protection against viral entry [86]. It is a Janus kinase inhibitor that has previously been administered to rheumatoid arthritis patients. Its use along with remdesivir for COVID-19 has been approved in the United States. Modest improvement in recovery time was reported in patients using this drug combination as compared to glucocorticoids [87, 88]. Several other drug therapies such as ivermectin are also being studied $[12,71,89]$.

\section{Vaccination: past, present, and future}

While no vaccine was released for SARS-CoV and MERS, the start of the vaccine study in those 2 viruses helped improve the speed of vaccine development for SARS-CoV-2. Studies targeting various molecular platforms were launched early on to find an effective vaccine against the virus. RNA vaccine studies focused on having a messenger RNA (mRNA) that can cause the build-up of foreign particles and lead to an adaptive immune response. Both the BNT162b2 vaccine (Pfizer-BioNTech COVID-19 vaccine) and mRNA 1273 vaccine (Moderna COVID-19 vaccine) are RNA vaccines. Pfizer-BioNTech COVID-19 vaccine reported a $95 \%$ efficacy as per data published on $10^{\text {th }}$ December 2020 [90]. The Moderna COVID-19 vaccine reported several positive results and had an efficacy of $94 \%$ [91].

An emergency use authorization for BNT162b2 vaccine (Pfizer-BioNTech COVID-19 vaccine) and mRNA 1273 vaccine (Moderna COVID-19 vaccine) was granted by the FDA in the United States for patients of ages 16 years and more and 18 years and more, respectively. Both vaccines are administered intramuscularly over 2 doses. For BNT162b2 (Pfizer-BioNTech COVID-19 vaccine) the second 
dose is given after 3 weeks, while the second dose of mRNA 1273 (Moderna COVID-19 vaccine) is given a month later. While it is highly advised to use the same vaccines for both doses, on January $21^{\text {st }}$ 2021 , the CDC issued recommendations for exceptional situations where if the first-dose vaccine cannot be determined, then any available mRNA COVID-19 vaccine can be given with an interval of at least 28 days to provide the complete dose [92].

Several other vaccines are also currently being developed, and some have been approved for use in some countries. The Oxford-AstraZeneca COVID-19 vaccine is an adenovirus vector vaccine [93] that has an efficacy ranging from $62 \%$ to $90 \%$ [94]. Its use has been approved in several countries such as India, Pakistan, Nepal, Brazil, and Argentina amongst many [95]. The BBIBP-CorV (Sinopharm) and CoronaVac (Sinovac) vaccines are inactivated SARS-CoV-2 vaccines, which have shown $79 \%$ and $65-91 \%$ efficacy, respectively [96100]. In an article published on $2^{\text {nd }}$ February 2021, Logunov et al. reported that the phase 3 trial of Gam-COVID-Vac, also known as Sputnik V, resulted in an overall efficacy of $91.6 \%$ efficacy [101]. Johnson \& Johnson issued a statement on $29^{\text {th }}$ January 2021 that their Single-Shot Janssen COVID-19 Vaccine had an 85\% efficacy in preventing severe outcome of COVID-19 and also 66\% efficacy at preventing moderate to severe COVID-19. It also demonstrated "complete protection against COVID-19-related hospitalization and death as of day 28" [102]. The company further announced on $4^{\text {th }}$ February that they have applied for Emergency Use Authorization from the FDA for their vaccine. Its main advantages also include a longer storage at $36-46^{\circ} \mathrm{F}\left(2.2-7.8^{\circ} \mathrm{C}\right)$ for at least 3 months, and they can produce 100 million doses in the first 6 months of 2021 to meet the demands in the United States [103, 104].

Some common reactogenicity symptoms have been reported with the administration of these vaccines, and they are mostly mild such as fever, chills, headache, and myalgias [105]. The CDC also reported that as of 23 December 2020, 21 anaphylaxis reactions were confirmed among the $1,893,360$ recipients of the Pfizer-BioNTech COVID-19 vaccine in the United States. Seventeen of those had a history of allergies or allergic reactions and 7 had an anaphylaxis in the past [106].

\section{Lockdowns and mental health during the pandemic}

In order to combat the spread of the virus, several countries issued strict lockdowns. Anyone violating the curfew would be arrested or charged [107]. However, some people believed that these rules were in violation of their freedom of choice, and several anti-lockdown as well as anti-mask movements and marches have been reported in various countries [108, 109]. Alison Thompson, who is a bioethics professor at the University of Toronto, suggested that "the opposition to masks speaks to an underlying mistrust of public health messaging and the science around coronavirus disease 2019 (COVID-19)" [110].

The lockdowns and changes in lifestyle have had a very heavy impact on the mental health of many individuals. Xiong et al. reported that higher rates of anxiety, depression, psychological distress, and stress as well as post-traumatic stress disorder were seen during the pandemic in the general population [111]. Health care workers have also been overburdened, and in some hospitals several coping mechanisms have been provided to help them [112, 113]. Sher hypothesized that the social isolation, uncertainty, and chronic stress of lockdowns and a pandemic can lead to an increased risk of suicidal thoughts, and they may peak later than the actual pandemic [114]. It has been strongly encouraged that people continue normal routine activities, exercise regularly, avoid alcoholic drinks and drugs, and keep a normal sleeping pattern during lockdowns. The general population has easy access to technology and can easily communicate and be in touch with each other while respecting social distancing protocols. Schools have used several media such as Skype and Zoom to teach their students while prioritizing their safety [115-119].

\section{Major hurdles during the year and what to expect now}

While the world was experiencing one of the worst pandemics in recent times, there were many factors that complicated the proper management of the spread of the virus. Several countries were at first hesitant to close their borders and issue lockdowns, and this led to a spike in the number of new cases as the virus spread in multiple crowded areas. Conspiracy theories about the virus as well as misinformation and downplaying the severity of the virus on social media worsened the efforts made to contain the spread [120-123]. The plan and action to protect and combat COVID-19 locally and internationally by the authorities in New Zealand and Australia were praiseworthy. They acted fast and issued border closures as well as major lockdowns to reduce the local spread [124]. The strict response from Taiwan resulted in only 909 cases and 8 deaths [125]. The island of Mauritius has also reported a very positive approach to the pandemic. They have shut down their international borders, and all passengers are required to undergo quarantine as well as multiple tests to rule out any trace of COVID-19. They also issued strict lock-downs, and it was illegal to spread any 
misinformation on social media regarding the pandemic [7].

There are many challenges ahead of us for 2021. With the introduction of several vaccines, proper education about their benefits as well as risks should be expanded to combat misinformation. The public should also be encouraged to use masks and respect the social distancing protocols set by several international bodies that can help prevent the spread of COVID-19. The idea of a "vaccine-passport" has also been mooted [126]. During this last year, several countries have recorded massive economic losses. Businesses have gone bankrupt with lockdowns, and there is a long road towards a "normalization" of life [127].

\section{Conclusions}

COVID-19 is an ongoing pandemic that has already crossed its 1-year anniversary, and the number of new cases and deaths is on the rise daily. However, with the approval of new vaccines, the world started the year 2021 with a more optimistic approach. The World Health Organization is investigating the sources and causes of the emergence of the virus, and strict measures should also be taken to prevent any possible SARS-CoV-3 or equivalent from surging in the next few years.

\section{Conflict of interest}

The authors declare no conflict of interest.

\section{References}

1. Ramphul K, Mejias SG. Coronavirus disease: a review of a new threat to public health. Cureus 2020; 12: e7276.

2. Krishnan A, Hamilton JP, Alqahtani SA, Woreta TA. A narrative review of coronavirus disease 2019 (COVID-19): clinical, epidemiological characteristics, and systemic manifestations. Intern Emergency Medicine 2021; https://doi.org/10.1007/s11739-020-02616-5.

3. Pneumonia of unknown cause - China. 2020. https:// www.who.int/csr/don/05-january-2020-pneumoniaof-unkown-cause-china/en/ (accessed 16th January 2021).

4. Zhou P, Yang XL, Wang XG, et al. A pneumonia outbreak associated with a new coronavirus of probable bat origin. Nature 2020; 579: 270-3.

5. Zhu N, Zhang D, Wang W, et al. A novel coronavirus from patients with pneumonia in China, 2019. N Engl J Med 2020; 382: 727-33.

6. The species Severe acute respiratory syndrome-related coronavirus: classifying 2019-nCoV and naming it SARS-CoV-2. Nature Microbiol 2020; 5: 536-44.

7. Kowlessur S, Ori B, Zimmet P, Tuomilehto J, Chitson P, Ramphul Y. Tackling the COVID-19 pandemic in paradise: the Mauritian experience. Lancet Diabetes Endocrinol 2020; 8: 878-9.

8. Amanat F, Krammer F. SARS-CoV-2 vaccines: status report. Immunity 2020; 52: 583-9.
9. Boopathi S, Poma AB. Novel 2019 coronavirus structure, mechanism of action, antiviral drug promises and rule out against its treatment. J Biomol Struct Dyn 2020: 1-10.

10. Pal M, Berhanu G, Desalegn C, Kandi V. Severe acute respiratory syndrome coronavirus-2 (SARS-CoV-2): an update. Cureus 2020; 12: e7423.

11. Lu R, Zhao X, Li J, et al. Genomic characterisation and epidemiology of 2019 novel coronavirus: implications for virus origins and receptor binding. Lancet 2020; 395: 565-74

12. Coronavirus disease 2019 (COVID-19): Epidemiology, virology, and prevention. 2021. https://www.uptodate. com/contents/coronavirus-disease-2019-covid-19-epidemiology-virology-and-prevention\#H1305971586 (accessed 20th January 2021).

13. Hu B, Guo H, Zhou P, Shi ZL. Characteristics of SARS-CoV-2 and COVID-19. Nat Rev Microbiol 2020; 19: 141-54.

14. Zheng J. SARS-CoV-2: an emerging coronavirus that causes a global threat. Int J Biol Sci 2020; 16: 1678-85.

15. Anand KB, Karade S, Sen S, Gupta RM. SARS-CoV-2: Camazotz's curse. Med J Armed Forces India 2020; 76: 136-41.

16. Chen L, Liu W, Zhang $\mathrm{Q}$, et al. RNA based mNGS approach identifies a novel human coronavirus from two individual pneumonia cases in 2019 Wuhan outbreak. Emerging Microbes Infect 2020; 9: 313-9.

17. Huang Y, Yang C, Xu XF, Xu W, Liu SW. Structural and functional properties of SARS-CoV-2 spike protein: potential antivirus drug development for COVID-19. Acta Pharmacol Sin 2020; 41: 1141-9.

18. Santos JC, Passos GA. The high infectivity of SARSCoV-2 B.1.1.7 is associated with increased interaction force between Spike-ACE2 caused by the viral N501Y mutation. bioRXiv 2021: DOI: https://doi. org/10.1101/2020.12.29.424708.

19. Volz E, Mishra S, Chand M, et al. Transmission of SARSCoV-2 Lineage B.1.1.7 in England: Insights from linking epidemiological and genetic data. bioRXiv 2021. https://doi.org/10.1101/2020.12.30.20249034.

20. Tegally $\mathrm{H}$, Wilkinson E, Giovanetti M, et al. Emergence and rapid spread of a new severe acute respiratory syndrome-related coronavirus 2 (SARS-CoV-2) lineage with multiple spike mutations in South Africa. medRxiv 2020: 2020.12.21.20248640.

21. Schroter RC. Social distancing for covid-19: is 2 metres far enough? BMJ 2020; 369: m2010.

22. Jones NR, Qureshi ZU, Temple RJ, Larwood JPJ, Greenhalgh T, Bourouiba L. Two metres or one: what is the evidence for physical distancing in covid-19? BMJ 2020; 370: m3223.

23. Guan WJ. Clinical characteristics of coronavirus disease 2019 in China. J Med Virol 2020; 382: 1708-20.

24. Li Q, Guan X, Wu P, et al. Early Transmission dynamics in Wuhan, China, of novel Coronavirus-infected pneumonia. N Engl J Med 2020; 382: 1199-207.

25. Chan JF, Yuan S, Kok KH, et al. A familial cluster of pneumonia associated with the 2019 novel coronavirus indicating person-to-person transmission: a study of a family cluster. Lancet 2020; 395: 514-23.

26. COVID-19 coronavirus pandemic. 2020. https://www. worldometers.info/coronavirus/ (accessed 16th October 2020).

27. Stringhini S, Wisniak A, Piumatti G, et al. Seroprevalence of anti-SARS-CoV-2 IgG antibodies in Geneva, Switzerland (SEROCOV-POP): a population-based study. Lancet 2020; 396: 313-9. 
28. Havers FP, Reed C, Lim T, et al. Seroprevalence of antibodies to SARS-CoV-2 in 10 sites in the United States, March 23-May 12, 2020. JAMA Intern Med 2020; 180: 1576-86.

29. Holshue ML, DeBolt C, Lindquist S, et al. First case of 2019 novel coronavirus in the United States. N Engl J Med 2020; 382: 929-36.

30. Harahwa TA, Lai Yau TH, Lim-Cooke MS, Al-Haddi S, Zeinah $M$, Harky A. The optimal diagnostic methods for COVID-19. Diagnosis 2020; 7: 349-56.

31. Symptoms. 2020. https://www.cdc.gov/coronavirus/2019 ncov/symptoms-testing/symptoms.html (accessed $20^{\text {th }}$ January 2021).

32. Stokes EK, Zambrano LD, Anderson KN, et al. Coronavirus disease 2019 case surveillance - United States, January 22-May 30, 2020. MMWR Morb Mortal Wkly Rep 2020; 69: 759-65.

33. Boscolo-Rizzo P, Borsetto D, Fabbris C, et al. Evolution of altered sense of smell or taste in patients with mildly symptomatic COVID-19. JAMA Otolaryngol Head Neck Surg 2020; 146: 729-32.

34. Wu Z, McGoogan JM. Characteristics of and Important lessons from the coronavirus disease 2019 (COVID-19) outbreak in China: summary of a report of 72314 cases from the chinese center for disease control and prevention. JAMA 2020; 323: 1239-42.

35. Meyerowitz-Katz G, Merone L. A systematic review and meta-analysis of published research data on COVID-19 infection fatality rates. Int J Infect Dis 2020; 101: 138-48.

36. Pastor-Barriuso R, Pérez-Gómez B, Hernán MA, et al. Infection fatality risk for SARS-CoV-2 in community dwelling population of Spain: nationwide seroepidemiological study. BMJ 2020; 371: m4509.

37. Aggarwal G, Lippi G, Lavie CJ, Henry BM. Diabetes mellitus association with coronavirus disease 2019 (COVID-19) severity and mortality: a pooled analysis. J Diabetes 2020; 12: 851-5.

38. Aggarwal G, Lippi G, Michael Henry B. Cerebrovascular disease is associated with an increased disease severity in patients with Coronavirus disease 2019 (COVID-19): a pooled analysis of published literature. Int J Stroke 2020; 15: 385-9.

39. Cheruiyot I, Henry B, Lippi G, et al. Acute kidney injury is associated with worse prognosis in COVID-19 patients: a systematic review and meta-analysis. Acta Biomed 2020; 91: e2020029.

40. Lippi G, Wong J, Henry BM. Hypertension in patients with coronavirus disease 2019 (COVID-19): a pooled analysis. Pol Arch Intern Med 2020; 130: 304-9.

41. Lippi G, Henry BM. Chronic obstructive pulmonary disease is associated with severe coronavirus disease 2019 (COVID-19). Respir Med 2020; 167: 105941.

42. Lippi G, Sanchis-Gomar F, Henry BM. Active smoking and COVID-19: a double-edged sword. Eur J Intern Med 2020; 77: 123-4

43. Lippi G, Plebani M. Procalcitonin in patients with severe coronavirus disease 2019 (COVID-19): a metaanalysis. Clin Chim Acta 2020; 505: 190-1.

44. Lippi G, Henry BM, Sanchis-Gomar F. Red blood cell distribution is a significant predictor of severe illness in coronavirus disease 2019. Acta Haematol 2020: 1-5. Doi: 10.1159/000510914

45. Lippi G, Mattiuzzi C. Hemoglobin value may be decreased in patients with severe coronavirus disease 2019. Hematol Transfus Cell Ther 2020; 42: 116-7.

46. Lippi G, Plebani M, Henry BM. Thrombocytopenia is associated with severe coronavirus disease 2019
(COVID-19) infections: a meta-analysis. Clin Chim Acta 2020; 506: 145-8.

47. Lippi G, Plebani M. Laboratory abnormalities in patients with COVID-2019 infection. Clin Chem Labor Med 2020; 58: 1131-4.

48. Lippi G, Wong J, Henry BM. Myalgia may not be associated with severity of coronavirus disease 2019 (COVID-19). World J Emergency Med 2020; 11: 193-4.

49. Ramphul K, Mejias SG, Ramphul Y. Headache may not be linked with severity of coronavirus disease 2019 (COVID-19). World J Emergency Med 2020; 11: 274.

50. Williamson EJ, Walker AJ, Bhaskaran K, et al. Factors associated with COVID-19-related death using OpenSAFELY. Nature 2020; 584: 430-6.

51. Richardson S, Hirsch JS, Narasimhan M, et al. Presenting characteristics, comorbidities, and outcomes among 5700 patients hospitalized with COVID-19 in the New York City Area. JAMA 2020; 323: 2052-9.

52. Onder G, Rezza G, Brusaferro S. Case-fatality rate and characteristics of patients dying in relation to COVID-19 in Italy. JAMA 2020; 323: 1775-6.

53. Petrilli CM, Jones SA, Yang J, et al. Factors associated with hospital admission and critical illness among 5279 people with coronavirus disease 2019 in New York City: prospective cohort study. BMJ 2020; 369: m1966.

54. Peckham H, de Gruijter NM, Raine C, et al. Male sex identified by global COVID-19 meta-analysis as a risk factor for death and ITU admission. Nat Commun 2020; 11: 6317

55. Kragholm K, Andersen MP, Gerds TA, et al. Association between male sex and outcomes of Coronavirus disease 2019 (Covid-19) - a Danish nationwide, register-based study. Clin Infect Dis 2020. doi: 10.1093/ cid/ciaa924.

56. Chen T, Wu D, Chen $\mathrm{H}$, et al. Clinical characteristics of 113 deceased patients with coronavirus disease 2019: retrospective study. BMJ 2020; 368: m1091.

57. Price-Haywood EG, Burton J, Fort D, Seoane L. Hospitalization and mortality among black patients and white patients with Covid-19. N Engl J Med 2020; 382: 2534-43.

58. Moore JT, Ricaldi JN, Rose CE, et al. Disparities in incidence of COVID-19 among underrepresented racial/ ethnic groups in counties identified as hotspots during June 5-18, 2020 - 22 States, February-June 2020. MMWR Morb Mortal Wkly Rep 2020; 69: 1122-6.

59. Gold JAW, Wong KK, Szablewski CM, et al. Characteristics and clinical outcomes of adult patients hospitalized with COVID-19 - Georgia, March 2020. MMWR Morb Mortal Wkly Rep 2020; 69: 545-50.

60. Gold JAW, Rossen LM, Ahmad FB, et al. Race, ethnicity, and age trends in persons who died from COVID-19United States, May-August 2020. MMWR Morb Mortal Wkly Rep 2020; 69: 1517-21.

61. Garg S, Kim L, Whitaker M, et al. Hospitalization rates and characteristics of patients hospitalized with laboratory-confirmed coronavirus disease 2019 - COVIDNET, 14 States, March 1-30, 2020. MMWR Morb Mortal Wkly Rep 2020; 69: 458-64.

62. Loke $\mathrm{YH}$, Berul $\mathrm{Cl}$, Harahsheh AS. Multisystem inflammatory syndrome in children: is there a linkage to Kawasaki disease? Trends Cardiovasc Med 2020; 30: 389-96.

63. Ramphul K, Mejias SG. Kawasaki disease: a comprehensive review. Arch Med Sci Atheroscler Dis 2018; 3: e41-5. 
64. Jiang L, Tang K, Levin M, et al. COVID-19 and multisystem inflammatory syndrome in children and adolescents. Lancet Infect Dis 2020; 20: e276-88.

65. Partner Updates. 2020. https://www.cdc.gov/mis-c/ hcp/ (accessed 20th January 2021).

66. Boushra MN, Koyfman A, Long B. COVID-19 in pregnancy and the puerperium: a review for emergency physicians. Am J Emerg Med 2021; 40: 193-98.

67. Kotlyar AM, Grechukhina O, Chen A, et al. Vertical transmission of coronavirus disease 2019: a systematic review and meta-analysis. Am J Obstet Gynecol 2021; 224: 35-53.e3.

68. Nicola M, O’Neill N, Sohrabi C, Khan M, Agha M, Agha R. Evidence based management guideline for the COVID-19 pandemic. Int I Surgery 2020; 77: 206-16.

69. Bhimraj A, Morgan RL, Shumaker AH, et al. Infectious diseases society of America guidelines on the treatment and management of patients with COVID-19. Clin Infect Dis 2020; doi: 10.1093/cid/ciaa478.

70. Liu Y, Yan LM, Wan L, et al. Viral dynamics in mild and severe cases of COVID-19. Lancet Infect Dis 2020; 20: 656-7.

71. Coronavirus Disease 2019 (COVID-19) Treatment Guidelines. 2021. https://www.covid19treatmentguidelines.nih.gov/ (accessed 20th January 2021).

72. Alhazzani W, Møller MH, Arabi YM, et al. Surviving sepsis campaign: guidelines on the management of critically ill adults with Coronavirus Disease 2019 (COVID-19). Intensive Care Med 2020; 46: 854-87.

73. Wiersinga WJ, Rhodes A, Cheng AC, Peacock SJ, Prescott HC. Pathophysiology, transmission, diagnosis, and treatment of coronavirus disease 2019 (COVID-19): a review. JAMA 2020; 324: 782-93.

74. Pascarella G, Strumia A, Piliego C, et al. COVID-19 diagnosis and management: a comprehensive review. J Intern Med 2020; 288: 192-206.

75. Ahmed MH, Hassan A. Dexamethasone for the treatment of coronavirus disease (COVID-19): a review. SN Comp Clin Med 2020: 1-10. doi: 10.1007/s42399-020-00610-8.

76. Tomazini BM, Maia IS, Cavalcanti AB, et al. Effect of dexamethasone on days alive and ventilator-free in patients with moderate or severe acute respiratory distress syndrome and COVID-19: the CoDEX randomized clinical trial. JAMA 2020; 324: 1307-16.

77. Sterne JAC, Murthy S, Diaz JV, et al. Association between administration of systemic corticosteroids and mortality among critically ill patients with COVID-19: a meta-analysis. JAMA 2020; 324: 1330-41.

78. Yao X, Ye F, Zhang M, et al. In Vitro antiviral activity and projection of optimized dosing design of hydroxychloroquine for the treatment of severe acute respiratory syndrome coronavirus 2 (SARS-CoV-2). Clin Infect Dis 2020; 71: 732-9.

79. Self WH, Semler MW, Leither LM, et al. Effect of Hydroxychloroquine on clinical status at 14 days in hospitalized patients with COVID-19: a randomized clinical trial. JAMA 2020; 324: 2165-76.

80. Peiffer-Smadja N, Rebeaud ME, Guihur A, MahamatSaleh Y, Fiolet T. Hydroxychloroquine and COVID-19: a tale of populism and obscurantism. Lancet Infect Dis 2020. doi: 10.1016/S1473-3099(20)30866-5.

81. Sheahan TP, Sims AC, Leist SR, et al. Comparative therapeutic efficacy of remdesivir and combination lopinavir, ritonavir, and interferon beta against MERS-CoV. Nat Commun 2020; 11: 222

82. Teimury A, Mahmoodi Khaledi E. Current options in the treatment of COVID-19: a review. Risk Manag Healthcare Policy 2020; 13: 1999-2010.
83. Pruijssers AJ, George AS, Schäfer A, et al. Remdesivir inhibits SARS-CoV-2 in human lung cells and chimeric SARS-CoV expressing the SARS-CoV-2 RNA polymerase in mice. Cell Rep 2020; 32: 107940.

84. Lynch HF, Bateman-House A, Joffe S. Emergency approvals for COVID-19: evolving impact on obligations to patients in clinical care and research. Ann Intern Med 2021; 174: 256-7.

85. Pau AK, Aberg J, Baker J, et al. Convalescent plasma for the treatment of COVID-19: perspectives of the $\mathrm{Na}$ tional Institutes of Health COVID-19 treatment guidelines panel. Ann Intern Med 2021; 174: 93-5.

86. Interleukin-6 Inhibitors. $2020 . \quad \mathrm{https} / / \mathrm{www}$. covid19treatmentguidelines.nih.gov/immunebased-therapy/immunomodulators/interleukin-6-inhibitors/ (accessed 20th January 2021).

87. Nguyen AA, Habiballah SB, Platt CD, Geha RS, Chou JS, McDonald DR. Immunoglobulins in the treatment of COVID-19 infection: proceed with caution! Clin Immunol 2020; 216: 108459.

88. Mehta P, McAuley DF, Brown M, Sanchez E, Tattersall RS, Manson JJ. COVID-19: consider cytokine storm syndromes and immunosuppression. Lancet 2020; 395: 1033-4.

89. Kaur H, Shekhar N, Sharma S, Sarma P, Prakash A, Medhi B. Ivermectin as a potential drug for treatment of COVID-19: an in-sync review with clinical and computational attributes. Pharmacol Rep 2021; 1-14.

90. Polack FP, Thomas SJ, Kitchin N, et al. Safety and efficacy of the BNT162b2 mRNA Covid-19 vaccine. 2020; 383: 2603-15.

91. Baden LR, El Sahly HM, Essink B, et al. Efficacy and safety of the mRNA-1273 SARS-CoV-2 vaccine. N Engl J Med 2021; 384: 403-16.

92. Interim Clinical Considerations for Use of mRNA COVID-19 Vaccines Currently Authorized in the United States. 2021

93. Investigating a vaccine against COVID-19. https://clinicaltrials.gov/ct2/show/NCT04400838 (accessed $25^{\text {th }}$ January 2021).

94. Voysey M, Clemens SAC, Madhi SA, et al. Safety and efficacy of the ChAdOx1 nCoV-19 vaccine (AZD1222) against SARS-CoV-2: an interim analysis of four randomised controlled trials in Brazil, South Africa, and the UK. Lancet 2021; 397: 99-111.

95. Rab S, Afjal, Javaid M, Haleem A, Vaishya R. An update on the global vaccine development for coronavirus. Diabetes Metab Syndrome 2020; 14: 2053-5.

96. Kim JH, Marks F, Clemens JD. Looking beyond COVID-19 vaccine phase 3 trials. Nat Med 2021; 27: 205-11.

97. Dong Y, Dai T, Wei Y, Zhang L, Zheng M, Zhou F. A systematic review of SARS-CoV-2 vaccine candidates. Signal Transduct Target Ther 2020; 5: 237.

98. Zhang Y, Zeng G, Pan H, et al. Safety, tolerability, and immunogenicity of an inactivated SARS-CoV- 2 vaccine in healthy adults aged 18-59 years: a randomised, double-blind, placebo-controlled, phase 1/2 clinical trial. Lancet Infect Dis 2021; 21: 181-92.

99. Qiu YZ, Yin WD. Safety and immunogenicity of Sinovac's prototype pandemic influenza H5N1 vaccines: a review on clinical trials. Influenza Other Respir Viruses 2008; 2: 237-42.

100. Guo W, Xu J, Wu J, et al. Safety and immunogenicity of seasonal inactivated influenza vaccine (split virion) and cross-reactive antibody responses to the H7N9 avian influenza virus. Zhonghua Liu Xing Bing Xue Za Zhi 2014; 35: 949-52.

101. Logunov DY, Dolzhikova IV, Shcheblyakov DV, et al. Safety and efficacy of an rAd26 and rAd5 vector-based 
heterologous prime-boost COVID-19 vaccine: an interim analysis of a randomised controlled phase 3 trial in Russia. Lancet 2021; 397: 671-81.

102. Johnson \& Johnson Announces Single-Shot Janssen COVID-19 Vaccine Candidate Met Primary Endpoints in Interim Analysis of its Phase 3 ENSEMBLE Trial. 2021. https://www.jnj.com/johnson-johnson-announcessingle-shot-janssen-covid-19-vaccine-candidate-metprimary-endpoints-in-interim-analysis-of-its-phase-3ensemble-trial (accessed 5th February 2021).

103. Johnson \& Johnson Applies For Emergency Use Au thorization For COVID-19 Vaccine. 2021. https:// www.npr.org/sections/coronavirus-live-updates/2021/02/04/964264102/johnson-johnson-applies-for-emergency-use-authorization-for-anti-covid-19-vaccin (accessed 5th February 2021 2021)

104. Johnson \& Johnson Announces Submission of Application to the U.S. FDA for Emergency Use Authorization of its Investigational Single-Shot Janssen COVID-19 VaccineCandidate.2021.https://www.jnj.com/johnsonjohnson-announces-submission-of-application-tothe-u-s-fda-for-emergency-use-authorization-of-its-investigational-single-shot-janssen-covid-19-vaccine-candidate (accessed 5th February 2021 2021).

105. What to Expect after Getting a COVID-19 Vaccine. 2021. https://www.cdc.gov/coronavirus/2019-ncov/ vaccines/expect/after.html (accessed $25^{\text {th }}$ January 2021).

106. Allergic Reactions Including Anaphylaxis After Receipt of the First Dose of Pfizer-BioNTech COVID-19 Vaccine - United States, December 14-23, 2020. MMWR Morb Mortal Wkly Rep 2021; 70: 46-51.

107. Al-Tammemi AB. The battle against COVID-19 in Jordan: an early overview of the Jordanian experience. Front Public Health 2020; 8: 188.

108. Karami A, Anderson M. Social media and COVID-19: characterizing anti-quarantine comments on Twitter. Proc Assoc Inf Sci Technol 2020; 57: e349.

109. Li T, Liu Y, Li M, Qian X, Dai SY. Mask or no mask for COVID-19: a public health and market study. PLoS One 2020; 15: e0237691.

110. Hapuhennedige S. Public health experts are learning from Canada's anti-mask protests. Canad Med Assoc J 2020; 192: E1274-e5.

111. Xiong J, Lipsitz O, Nasri F, et al. Impact of COVID-19 pandemic on mental health in the general population: a systematic review. J Affect Disord 2020; 277: 55-64.

112. Bohlken J, Schömig F, Lemke MR, Pumberger M, Riedel-Heller SG. COVID-19 pandemic: stress experience of healthcare workers - a short current review. Psychiatr Prax 2020; 47: 190-7.

113. Balasubramanian A, Paleri V, Bennett R, Paleri V. Impact of COVID-19 on the mental health of surgeons and coping strategies. Head Neck 2020; 42: 1638-44.

114. Sher $L$. The impact of the COVID-19 pandemic on suicide rates. QJM 2020; 113: 707-12.

115. Wilcha RJ. Effectiveness of virtual medical teaching during the COVID-19 crisis: systematic review. JMIR Med Educat 2020; 6: e20963.

116. Theoret C, Ming X. Our education, our concerns: the impact on medical student education of COVID-19. Med Educ 2020; 54: 591-2.

117. Sidpra J, Gaier C, Reddy N, Kumar N, Mirsky D, Mankad K. Sustaining education in the age of COVID-19: a survey of synchronous web-based platforms. Quant Imaging Med Surg 2020; 10: 1422-7.

118. Radu MC, Schnakovszky C, Herghelegiu E, Ciubota riu VA, Cristea I. The impact of the COVID-19 pandemic on the quality of educational process: a student survey. Int J Environ Res Public Health 2020; 17: 7770.

119. Pozo-Rico T, Gilar-Corbí R, Izquierdo A, Castejón JL. Teacher training can make a difference: tools to overcome the impact of COVID-19 on Primary schools. an experimental study. Int J Environm Res Public Health 2020; 17: 8633.

120. Carrion-Alvarez D, Tijerina-Salina PX. Fake news in COVID-19: a perspective. Health Promot Perspect 2020; 10: 290-1.

121. Hartley K, Vu MK. Fighting fake news in the COVID-19 era: policy insights from an equilibrium model. Policy Sci 2020: 1-24. doi: 10.1007/s11077-020-09405-z.

122. Romer D, Jamieson $\mathrm{KH}$. Conspiracy theories as barriers to controlling the spread of COVID-19 in the U.S. Soc Sci Med 2020; 263: 113356.

123. Georgiou N, Delfabbro P, Balzan R. COVID-19-related conspiracy beliefs and their relationship with perceived stress and pre-existing conspiracy beliefs. Pers Individ Dif 2020; 166: 110201

124. Baker MG, Wilson N, Anglemyer A. Successful elimination of Covid-19 transmission in New Zealand. N Engl J Med 2020; 383: e56.

125. Summers DJ, Cheng DHY, Lin PHH, et al. Potential lessons from the Taiwan and New Zealand health responses to the COVID-19 pandemic. Lancet Regional Health 2020; 4: 100044.

126. Phelan AL. COVID-19 immunity passports and vaccination certificates: scientific, equitable, and legal challenges. Lancet 2020; 395: 1595-8.

127. Carroll N, Conboy K. Normalising the "new normal": Changing tech-driven work practices under pandemic time pressure. Int J Inform Manag 2020; 55: 102186. 